\title{
The Kanizsa square does not engender a configural superiority effect
}

\author{
BIRGITTA DRESP \\ Neurologische Klinik der Universitat Freiburg, Freiburg, Germany
}

(Claude Bonnet, Sponsor)

\begin{abstract}
The figure-ground context provided by a Kanizsa square does not facilitate the identification of the orientation of a line segment. This observation, in addition to earlier findings, leads to the conclusion that figures with illusory contours do not seem to engender a "configural superiority effect." The theoretical consequences will be addressed briefly in the discussion.
\end{abstract}

Several authors have emphasized the idea that organized stimuli or forms are perceptually "superior" compared with patterns from which no salient structure emerges. The fact that visual detail is processed faster and more accurately with structured stimuli, forms, or objects would be a consequence of this configural superiority (Pomerantz, Sager, \& Stoever, 1977; Weisstein \& Harris, 1974; Wong \& Weisstein, 1982)..Configural or object-superiority effects have been observed in tasks in which a subject has to identify the orientation of a small line sègment that is tilted to the left or to the right. The percentage of correct responses is found to be higher, and reaction time shorter, when the line segment is presented in a figure or a context, compared with when it is shown on a background, or in a noncontext (Pomerantz, 1981; Pomerantz et al., 1977; Wong \& Weisstein, 1982).

Wong and Weisstein (1982) reported a configural superiority effect in Rubin's reversible figure; one can alternately perceive a vase in the center or two opposite face profiles (Rubin, 1921). Their observers were asked to focus attention either on the vase or on one of the faces during the experiment. The results showed that the orientation of a slightly tilted line segment is identified faster and more accurately when it is presented in the part of the stimulus that is seen as the figure. The authors concluded that figure-ground segregation must play a critical role in the production of these effects.

Illusory forms such as the Kanizsa square (Figure 1a) give rise to a figure-ground percept, in which the figure is perceived as being darker than the background (e.g., Kanizsa, 1979). This effect has been measured psychophysically and was found to be strongest when the gap between the inducing elements is small (e.g., Dresp, Lorenceau, \& Bonnet, 1990). The present experiment investigates whether this illusory figure-ground percept engenders a configural superiority effect similar to the one reported for Rubin's reversible figure.

Address correspondence to B. Dresp, Neurologische Klinik der Universität Freiburg, Abteilung für Neurophysiologie, Hansastrasse 9, 7800 Freiburg, Germany.

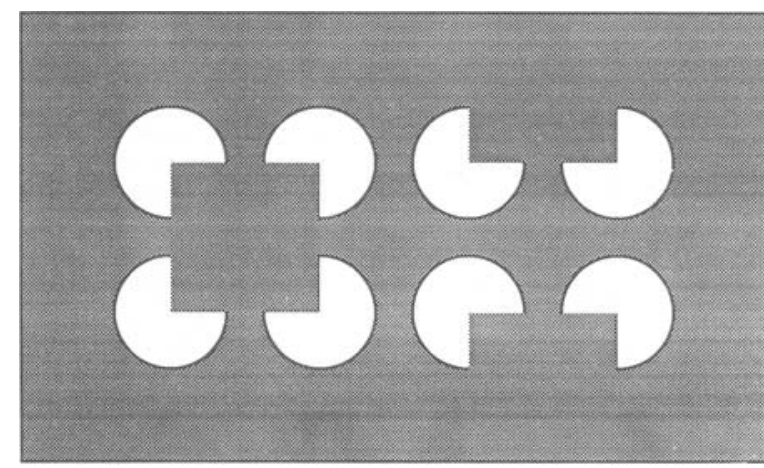

(a)

Figure 1. A Kanizsa square with white inducing elements on a dark background (a). This figure gives rise to a figure-ground percept with darkness enhancement in the center. Also shown is a control pattern without figure-ground structure (b). Both stimuli were used as context in this experiment.

\section{METHOD}

\section{Stimuli}

The figures used in this experiment were two versions of a Kanizsa square (Figures $1 \mathrm{a}$ and $1 \mathrm{~b})$ with white inducing elements $\left(68 \mathrm{~cd} / \mathrm{m}^{2}\right)$ on a gray background $\left(10 \mathrm{~cd} / \mathrm{m}^{2}\right)$. One version gives rise to a figureground percept in the center (Figure 1a), and the other does not (Figure $1 \mathrm{~b}$ ). The stimuli were presented on a high-resolution video screen $(1,024 \times 768$ pixels $)$, generated through an IBM-compatible PC using a special graphics adaptor. The whole length of one side of the Kanizsa square was $1^{\circ}$ of visual angle; the diameter of an inducing element was $15^{\prime}$ of arc. The gap between inducers was $30^{\prime}$ of arc in both figures.

\section{Procedure}

A line segment was presented in the center of one of the displays for about $16 \mathrm{msec}$ (one frame). In an additional control condition, it was presented on a plain gray field. The luminance of the line segment was above threshold $\left(35 \mathrm{~cd} / \mathrm{m}^{2}\right)$. It was flashed, in random order, slightly tilted to the left or to the right, and it was announced by a brief sound signal. The angle of tilt was $1^{\circ}$ from the vertical, the length of the segment was $6^{\prime}$ of arc, and it was $3^{\prime}$ of arc thick. All these values come close to those reported by Wong \& Weisstein (1982) in their experiments with the Rubin figure.

A two-alternative forced-choice procedure was used to measure the speed (RT) and the accuracy (percentage of correct responses) with which 
the orientation of the line segment was identified. The observer had to press a response key on his/her left when it was judged that the segment was tilted to the left, and a response key on the right when it was judged that it was tilted to the right. The subjects were instructed to respond as quickly as possible, without making errors. Their head position was stabilized by means of a head-and-chin support. The experiment took place in a dark room. Ten blocks of 50 trials were run for each experimental condition and with each subject.

\section{Subjects}

Three trained observers participated in the study, including the author. The subjects had normal vision.

\section{RESULTS}

The results of this experiment are shown in Table 1. Mean reaction times were calculated for each condition and observer, as well as an accuracy index $\left(\mathrm{A}^{\prime}\right)$. $\mathrm{A}^{\prime}$ usually varies between .50 (chance level) and $1(100 \%$ correct responses).

In the condition in which the line segment was presented on a plain gray field, accuracy $\left(\mathrm{A}^{\prime}\right)$ is found to vary between .76 and .83 , and RT between 374 and $401 \mathrm{msec}$. In the Kanizsa square condition, $\mathrm{A}^{\prime}$ varies between .73 and .82, RT between 408 and $423 \mathrm{msec}$, and in the control figure, mean values for $\mathrm{A}^{\prime}$ range from .70 and .83 , and mean RT varies between 415 and $435 \mathrm{msec}$. The data show that there is no systematic difference in $A^{\prime}$ or RT between experimental conditions.

Table 1

Accuracy Index ( $\left.\mathbf{A}^{\prime}\right)$ and Reaction Times (RT) for Each Condition and Subject

\begin{tabular}{lccc}
\hline & \multicolumn{3}{c}{ Condition } \\
\cline { 2 - 4 } Subject & Kanizsa Square & \multicolumn{1}{c}{ Control Figure } & Plain Field \\
\hline & \multicolumn{3}{c}{$\mathbf{A}^{\prime}$} \\
F.F. & .73 & .70 & .77 \\
B.D. & .81 & .83 & .82 \\
A.D. & .82 & .79 & .79 \\
$M$ & .79 & .77 & .79 \\
& \multicolumn{2}{c}{ RT (in Milliseconds) } \\
F.F. & 423 & 435 & \\
B.D. & 409 & 415 & 401 \\
A.D. & 408 & 418 & 374 \\
$M$ & 413 & 423 & 381 \\
\hline
\end{tabular}

Note-The data indicate no systematic difference in reaction times or accuracy between the different experimental conditions.

\section{DISCUSSION}

The configural superiority effect found with the Rubin figure by Wong and Weisstein (1982) could not be replicated here with the Kanizsa square. The figure-ground context in this experiment did not improve the observers' ability to identify the orientation of a briefly presented line segment. Performance was neither faster nor more accurate, using the illusory figure.

Pomerantz, Goldberg, Golder, and Tetewsky (1981) have drawn the same conclusion from a similar experiment with the Kanizsa square. Although illusory borders can facilitate dot localization, they found, in a second experiment, that an illusory contour did not help in a task in which the observers had to identify the orientation of a nearby presented line segment, whereas a real contour did. This result, together with the present findings, suggests that figures with illusory contours do not provide the information that is necessary for a configural superiority effect to occur. As a consequence, the determinants of this effect would essentially be contour information or orientational cues provided by lines, and not figure-ground segregation per se. This assumption finds support in the fact that configural or object-superiority effects have, hitherto, only been reported in figures with line contours (Pomerantz et al., 1977; Weisstein \& Harris, 1974; Wong \& Weisstein, 1982). Further studies will be necessary to assess the influence of contour and orientational cues on context-superiority effects, independently from figure-ground segregation

\section{REFERENCES}

Dresp, B., Lorenceau, J., \& BonNet, C. (1990). Apparent brightness enhancement in the Kanizsa square with and without illusory contour formation. Perception, 19, 483-489.

KANIZSA, G. (1979). Organization in vision: Essays in Gestalt perception. New York: Praeger.

Pomerantz, J. R., (1981). Perceptual organization in information processing. In M. Kubovy \& J. R. Pomerantz (Eds.), Perceptual organization (pp. 141-180). Hillsdale, NJ: Erlbaum.

Pomerantz, J. R., Goldberg, D. M., Golder, P. S., \& Tetewsky, S. (1981). Subjective contours can facilitate performance in a reactiontime task. Perception \& Psychophysics, 29, 605-611.

Pomerantz, J. R., Sager, L. C., \& Stoever, R. J. (1977). Perception of wholes and their component parts: Some configural superiority effects. Journal of Experimental Psychology: Human Perception \& Performance, 3, 422-435.

RUBIN, E. (1921). Visuell wahrgenommene Figuren. Kopenhagen: Gyldendals.

WeissteIn, N., \& Harris, C. S. (1974). Visual detection of line segments: An object superiority effect. Science, 186, 752-755.

WONG, E., \& WEISSTEIN, N. (1982). A new perceptual context-superiority effect: Line segments are more visible against a figure than against a ground. Science, 218, 587-589.

(Manuscript received October 26, 1992.) 